\title{
Non-tidal aliasing in seasonal sea-level variability and annual Rossby waves as observed by satellite altimetry
}

\author{
G. Chen ${ }^{1}$, R. Ezraty ${ }^{2}$ \\ ${ }^{1}$ Ocean Remote Sensing Institute, Ocean University of Gingdas, 5 Yushau Road, Gingdas 266003, China \\ ${ }^{2}$ Département d'Océanographie Spatiale, Centre de Brest, IFREMER, B.P. 70, F-29280 Plouzané, France \\ Tel: +3 02982242 99; Fax: +302982245 33; e-mail: rezraty@ifremer.fr
}

Received: 5 August 1996 / Revised: 15 January 1997 / Accepted: 17 March 1997

\begin{abstract}
It is becoming well known that aliasing associated with ocean tides could be a major source of systematic error in altimeter sea-level measurements, due to asynoptic sampling and imperfect tide modelling. However, it has been shown that signals of non-tidal origin may also contribute significantly to the observed aliasing. In this paper, numerical simulations are performed to demonstrate the full aliasing potential associated with altimeter observations of seasonal sealevel variability and annual Rossby waves. Our results indicate that ignorance of non-tidal aliasing may lead to the possibility of underestimating the total aliasing and misinterpreting or overlooking existing geophysical phenomena. Therefore, it is argued that an entire aliasing picture should be kept in mind when satellite altimeter data are analysed.
\end{abstract}

\section{Introduction}

The accuracy of altimetric sea-level measurements has been steadily improving towards a striking level of 1-2 cm during the past few years ( $\mathrm{Fu}$ et al., 1994; Cheney et al., 1994; Stammer and Wunsch, 1994; Shum et al., 1995; Le Traon et al., 1995), thanks to the significant advances in satellite technology, remotesensing instruments, as well as geophysical modelling and data processing. With considerable minimization of the uncertainties in orbit determination and environmental corrections, an intrinsic systematic source of error in altimeter measurements known as aliasing, resulting from asynoptic sampling, becomes an emerging challenge to many geophysical applications. This can be seen from the fact that, in recent altimetric studies, aliasing is a frequently mentioned source of error (e.g.

Correspondence to: R. Ezraty
Jacobs et al., 1992, 1993; Schlax and Chelton, 1994a,b; Le Provost et al., 1994; Stammer and Wunsch, 1994; Aoki et al., 1995; Chen and Ezraty, 1996).

Alias problems in satellite altimetry are usually addressed in connection with ocean tides, which are most easily detectable due to their well-defined frequencies associated with high energies. However, knowing that the frequency spectrum of sea level is continuous, infinite and geographically varying, the tide-only alias consideration is incomplete in theory and inadequate in reality. As shown by Chen and Ezraty (1996), aliasing in satellite altimetry is a $4 \mathrm{D}(x, y, z$ and $t)$ process involving all signals within a certain temporal and spatial domain. Although non-tidal aliasing energies are often smaller than tidal ones, keeping in mind that aliasing in altimeter sea-level observations is an accumulating process, the overall non-tidal contribution may not always be negligible. On the other hand, significant energy highs of nontidal origin have been found at periods ranging from several days to several months in various world oceans. For example, the existence of a barotropic planetary oscillation resulting from low-mode inertia-gravity waves in the Pacific Ocean is evidenced by three energy peaks centred at 3.0, 4.0 and 5.3 days in the sea-level spectrum (Luther, 1982; Wunsch and Gill, 1976); energy highs are identified along $5^{\circ} \mathrm{N}$ for periods of 28-40 days and along $12^{\circ} \mathrm{N}$ for periods of $50-90$ days, associated with sea-level oscillations along two shear fronts of the Pacific north equatorial countercurrent (Périgaud, 1990). Since the alias-free periods for recent altimeters, namely, Geosat, ERS-1,2 (35-day repeat orbit) and TOPEX/ POSEIDON, are 34.1, 70.0 and 19.8 days, respectively, many of the mentioned dynamic events which produce energy highs are potential candidates for altimetric aliasing. Therefore, we believe it is important to bear a complete theoretical aliasing picture in mind when making geophysical interpretations of altimeter sea-level measurements.

The main purpose of this paper is to demonstrate the full aliasing potential associated with altimeter-observed seasonal sea-level variability and annual Rossby waves. 
In doing so, numerical experiments are designed under previously developed theory to simulate the overall aliasing involved in each case. These two examples are selected because, on one hand, they are geophysically important and observationally favourable; and on the other, they are aliasing representative and cover all four dimensions of the problem. The rest of the paper is organized as follows: a brief summary of temporal and spatial aliasings in satellite altimetry is provided in Sect. 2; parallel descriptions of aliasing potentials involved in altimetric observations of seasonal sea-level variability and annual Rossby waves are presented in Sects. 3 and 4, respectively; some concluding remarks are given in Sect. 5 .

\section{A brief summary of altimetric aliasing}

A detailed analysis of some aspects of the alias effects associated with Geosat, ERS and TOPEX/POSEIDON altimeters has been carried out by Chen and Ezraty (1996). A brief summary of the results is presented here.

Two key parameters in addressing temporal and spatial aliasings are the alias period $T_{a}$ and alias wavelength $\lambda_{a} . T_{a}$ may be expressed as a function of satellite orbital repeat period $T_{s}$ and the original period of the signal $T_{o}$,

$T_{a}=\frac{T_{s}}{\frac{T_{s}}{T_{o}}-\left[\frac{T_{s}}{T_{o}}+0.5\right]}$,

where $[X]$ is the greatest integer less than or equal to $X$, and $X$ denotes an arbitrary argument.

Spatial aliasing in satellite altimetry is more complicated because of its along-track (near meridional) and cross-track (zonal) anisotropy. For the purpose of this study, we only focus on cross-track aliasing which is closely related to temporal aliasing. On the assumption that a harmonic signal has locally constant amplitude and phase, the zonal alias wavelength can be written as

$\lambda_{a, n}=\frac{\Delta x}{n+\left(\frac{\Delta t}{T_{o}}-\left[\frac{\Delta t}{T_{o}}+0.5\right]\right)-\frac{\Delta t}{T_{a}}}, \quad\left(T_{o}<2 T_{s}\right)$,

where $\Delta x$ and $\Delta t$ are space- and time-shifts between two adjacent longitude nodes at a given latitude, $n$ is an integer. Equation (2) states that there is an infinite number of spatial aliases for each harmonic signal. In most cases, however, only the primary alias wavelength $(n=0)$ is of practical importance, since shorter wavelengths usually cannot be resolved by altimeter measurements.

It is found that in the time-domain, the alias period appears as a non-periodic $\delta$-like function with respect to the original period of the signal (Fig. 1). In the spacedomain, the alias wavelength varies with the original period as a step-like function. Note that the zonal alias wavelengths are independent of their original wavelengths (see Eq. (2)). In other words, the real zonal scales of the original signals within the Nyquist band $\left(T_{o}<2 T_{S}\right)$ cannot be reflected in the observed crosstrack wavelengths, no matter how small $\Delta x$ is.
The alias periods and the primary zonal alias wavelengths of six major tidal constituents for Geosat, ERS and TOPEX/POSEIDON are listed in Table 1. Note that the alias wavelengths are expressed in the unit of degrees of longitude which have the advantage of being constants with respect to latitude.

\section{Case 1: seasonal sea-level variability}

Seasonality is one of the fundamental features of the ocean-atmosphere system. This is basically because most of the primary forcings, including wind stress, heating, rainfall and evaporation, are at annual and semiannual frequencies (Jacobs et al., 1992). Characterization of seasonal variation has been proven to be an important step towards a better understanding of many atmospheric and oceanic processes. This is also the case for sea level.

Seasonal variations of sea level have been analysed on both global and regional scales since the year-long satellite altimeter data became available in the late 1980s. Zlotnicki et al. (1989) study the seasonal variability in global sea level observed with Geosat altimetry. Annual, semiannual and interannual variabilities of the Southern Ocean sea level are examined by Chelton et al. (1990) with 26-month Geosat data using empirical orthogonal functions. Jacobs et al. (1992) obtain the global structure of the annual and semiannual sea surface height variability from 2 years of Geosat data by the least-squares technique. The annual cycle of sea-level variation in the western tropical Atlantic is derived by Didden and Schott (1992) from Geosat data using objective analysis. Annual sea level variation in the southern tropical Indian Ocean is investigated by Périgaud and Delecluse (1992) using both Geosat data and numerical simulations. Provost and Le Traon (1993) analyse the spatial and temporal scales of sea-level variability in the Brazil-Malvinas Current confluence region with a focus on the dominance of semiannual period. More recently, new efforts have been made to reinvestigate the seasonal sea-level changes by TOPEX/POSEIDON altimetry, in the hope that better results could be obtained due to the significant improvements in its data quality (Stammer and Wunsch, 1994; Tapley et al., 1994; Knudsen, 1994; Cheney et al., 1994; Nerem et al., 1994).

Browsing through the literature, one may easily find that although there are some general conclusions on global-scale sea-level variations among various authors, the scatter, and sometimes, random nature of the results is also evident, particularly on regional and semiannual scales. As pointed out by Zlotnicki et al. (1989) and confirmed by other investigators, it is difficult to discern coherent seasonal sea-level changes for most of the world oceans. One may be impressed by the unexpectedly low percentage of sea-level variances explained by the annual and semiannual cycles, roughly $20 \%$ and $10 \%$, respectively. In addition, qualitative comparisons between similar results derived from TOPEX/POSEIDON and Levitus atlas (Levitus, 1982) indicate that the 

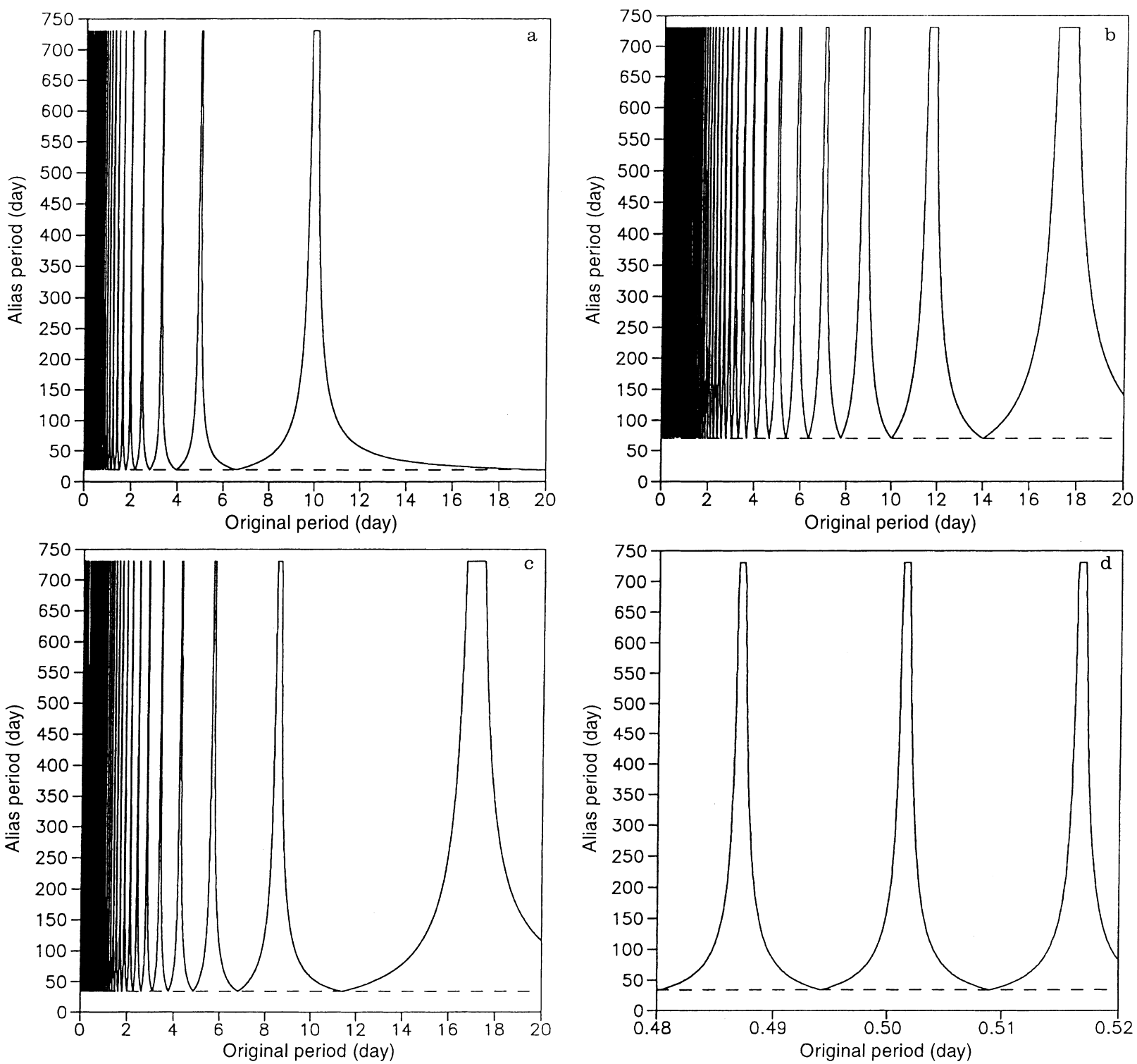

Fig. 1a-d. Alias period as a function of original period of a harmonic signal under the sampling schemes of a TOPEX/POSEIDON, b ERS (35-day repeat orbit) and $\mathbf{c}$ Geosat; $\mathbf{d}$ is a zoom of $\mathbf{c}$ centred at 0.5

days on the axis of original period. The dashed lines indicate the lower limit of the alias period, and the upper limit is cut at 730 days

differences are considerable and sometimes inconsistent. For example, in the equatorial region, TOPEX/POSEIDON shows a much larger annual variation than Levitus, while in the southern hemisphere, the annual variation is quite small in TOPEX/POSEIDON relative to Levitus (Nerem et al., 1994). Quantitative compari-

sons between TOPEX/POSEIDON and tide gauge results show a correlation of 0.74 for the annual cycle, but only 0.25 for the semiannual cycle (Knudsen, 1994), which is far from being significant. These poor statistics imply that it is often difficult to interpret or compare such results in a meaningful and reliable way. Several

Table 1. Alias periods and primary alias wavelengths of six major tidal constituents under Geosat, ERS (35-day repeat orbit) and TOPEX/ POSEIDON sampling schemes. The direction of alias propagation is denoted as $\mathrm{E}$ for east and $\mathrm{W}$ for west

\begin{tabular}{|c|c|c|c|c|c|c|c|}
\hline \multirow[t]{2}{*}{ Signal } & \multirow[t]{2}{*}{$T_{o}$ (day) } & \multicolumn{3}{|l|}{$T_{a}$ (day) } & \multicolumn{3}{|l|}{$\lambda_{a, 0}(\mathrm{deg})$} \\
\hline & & Geosat & ERS & $\mathrm{T} / \mathrm{P}$ & Geosat & ERS & $\mathrm{T} / \mathrm{P}$ \\
\hline M2 & 0.5175250 & 317.11 & 94.49 & 62.11 & $8.00 \mathrm{~W}$ & $8.79 \mathrm{E}$ & $9.01 \mathrm{E}$ \\
\hline S2 & 0.5000000 & 168.82 & $\infty$ & 58.74 & $179.90 \mathrm{E}$ & 179.76 & $183.01 \mathrm{~W}$ \\
\hline $\mathrm{N} 2$ & 0.5274311 & 52.07 & 97.39 & 49.53 & $4.09 \mathrm{E}$ & $4.29 \mathrm{~W}$ & $9.01 \mathrm{~W}$ \\
\hline $\mathrm{K} 1$ & 0.9972695 & 175.45 & 365.24 & 173.19 & $359.80 \mathrm{E}$ & $359.53 \mathrm{E}$ & $366.03 \mathrm{~W}$ \\
\hline $\mathrm{O} 1$ & 1.0758059 & 112.95 & 75.07 & 45.71 & $8.18 \mathrm{~W}$ & $8.58 \mathrm{E}$ & $9.24 \mathrm{E}$ \\
\hline P1 & 1.0027454 & 4465.95 & 365.25 & 88.89 & $359.80 \mathrm{E}$ & $359.53 \mathrm{~W}$ & $366.03 \mathrm{~W}$ \\
\hline
\end{tabular}


reasons have been suggested on the altimeter side which might be responsible for the observed incoherence, among them interannual sea-level variability and tidal aliasing are thought to be important (Chelton et al., 1990; Jacobs et al., 1992). Based on the descriptions in Sect. 1, however, we speculate that non-tidal aliasing is also a possible source of contamination. In this section, we are going to demonstrate this effect by numerical simulation and discuss its potential consequences.

The simulation scheme is straightforward. We consider the case of Geosat which has an intermediate orbit period $\left(T_{s}=17.0505\right.$ days $)$ among available altimeters. Suppose we have a harmonic signal, $s(t)$, with an annual period, a unit amplitude and an initial phase of zero,

$s(t)=\cos (2 \pi t / 365.24)$,

where $t$ is the time in day; and a perturbation, $n(t)$, with the same amplitude but a varying period $T$ (in day) and a random initial phase $\varphi_{0}$ between 0 and $2 \pi$,

$n(t)=\cos \left(2 \pi t / T+\varphi_{0}\right)$.

The combined signal and perturbation sampled by Geosat altimeter is therefore,

$G\left(t_{i}\right)=\cos \left(2 \pi t_{i} / 365.24\right)+\cos \left(2 \pi t_{i} / T+\varphi_{0}\right)$,

where $t_{i}=i \times 17.0505$ (day), and $i$ is an integer. In the present case, the sampling duration and the maximum period of the perturbation are limited to 2 and 5 years, respectively, i.e., $0 \leq t_{i} \leq 365.24 \times 2$ and $0 \leq T \leq$ $365.24 \times 5$. The sampled data set $G\left(t_{i}\right)$ is then used to recover the annual harmonic signal expressed as,

$R(t)=a \times \cos (2 \pi t / 365.24)+b \times \sin (2 \pi t / 365.24)$,

where $a$ and $b$ are regression coefficients. This is done by a running least squares with respect to $T$, on the assumption that $R\left(t_{i}\right)=G\left(t_{i}\right)$. Finally, the amplitude and phase of the recovered signal can be obtained by,

$A=\left(a^{2}+b^{2}\right)^{1 / 2}$

and

$\theta=\arctan (b / a)$.

The recovered amplitude of the annual harmonic signal as a function of perturbation period is shown in Fig. 2. Within the Nyquist band $\left(T<2 T_{s}\right)$, the recovered amplitude basically follows its original unit value but with numerous spikes and lobes ranging from 0 to 2 (Fig. 2a), which is mainly a reflection of aliasing. Comparing Figs. 1c and 2a, one recognizes that a spike

Fig. 2a-c. The recovered amplitude of an annual harmonic signal with respect to the perturbation period which covers a 0-20 days, and b 20-2000 days; c is a zoom of a, showing the details of the spike pairs. The simulation is performed on Geosat ascending tracks for a duration of 2 years. The ratio of amplitude of signal versus perturbation is 1
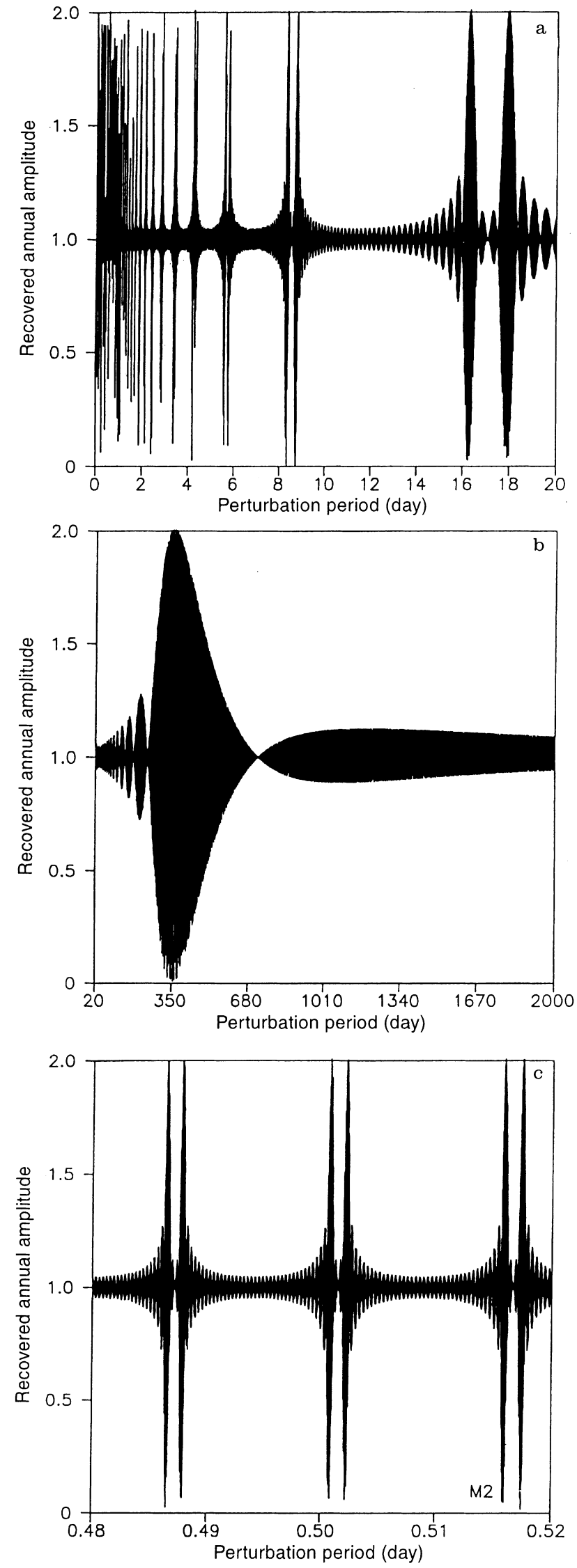
occurs when the alias period of $T$ equals 1 year. In fact, these spikes always appear in pairs (see Fig. 2c for a zoom), since $T$ intersects a given value twice within each alias oscillation (see also Fig. 1d). The central locations of the spike pairs can be approximated as,

$$
T_{c}=T_{s} / i, \quad(i=1,2,3, \ldots \ldots)
$$

It is obvious that the recovered amplitude of the annual signal is very sensitive to any perturbation with a period at or near these spikes. In the case of Geosat, the period of the M2 tide, 0.517525 day, happens to be very close to the left spike of the third pair in Fig. 2c, which is why its contamination to the annual cycle is so remarkable (see Jacobs et al., 1992). Meanwhile, one must realize that the M2 tide is only one of the infinite number of potential perturbations, although the most energetic one in the majority of the world oceans, whose periods fall into the sensitive bands (Fig. 2a,c). As we have pointed out, the frequency spectrum of the sea level is continuous and infinite, the contributions of other non-tidal perturbations at sensitive periods are also inevitable. In the Pacific Ocean, for instance, the low-mode inertiagravity waves with energy highs between 4-6 days (Luther, 1982), or tropical instability waves with periods between 28-40 days along $5^{\circ} \mathrm{N}$ (Périgaud, 1990) could be real examples of such perturbations. Unfortunately, the temporal and spatial irregularities of most of the non-tidal perturbations usually make them very difficult to identify and quantify. However, the existence of such contamination potentials needs to be equally acknowledged and taken into account, especially in regions where systematic wave propagation exists.

Beyond the Nyquist period, the frequency interference becomes less intensive but more consistent, i.e., the probability for an annual harmonic to be contaminated is increased (Fig. 2b). Note that the black area in Fig. 2 is proportional to the overall extent of interference. Signals with periods between 34.1 and 200 days only have slight influence on the recovered annual amplitude. In contrast, signals falling into the period band between 200 and 600 days have remarkable contributions (Fig. $2 b$ ). In a sense, a large part of the recovered amplitude actually corresponds to an average energy of this band rather than a single annual frequency. Noticeably, a non-interference point is located at 730 days, beyond which the contamination becomes almost frequency independent. This confirms the argument that the altimeter observed annual cycle will inevitably include part of the interannual variabilities.

The recovered phase of the annual harmonic signal as a function of perturbation period is plotted in Fig. 3. It is easy to recognize that the deviation pattern of phase recovery is similar to that of the amplitude (Fig. 2). This suggests that aliasing creates coherent impacts on both amplitude and phase within the Nyquist band. Phase shifts as large as $\pm 60^{\circ}$ are found around the spikes, while at locations other than these, the shifts are generally small, less than a few degrees in the Nyquist band and less than $10^{\circ}$ beyond that band. It is
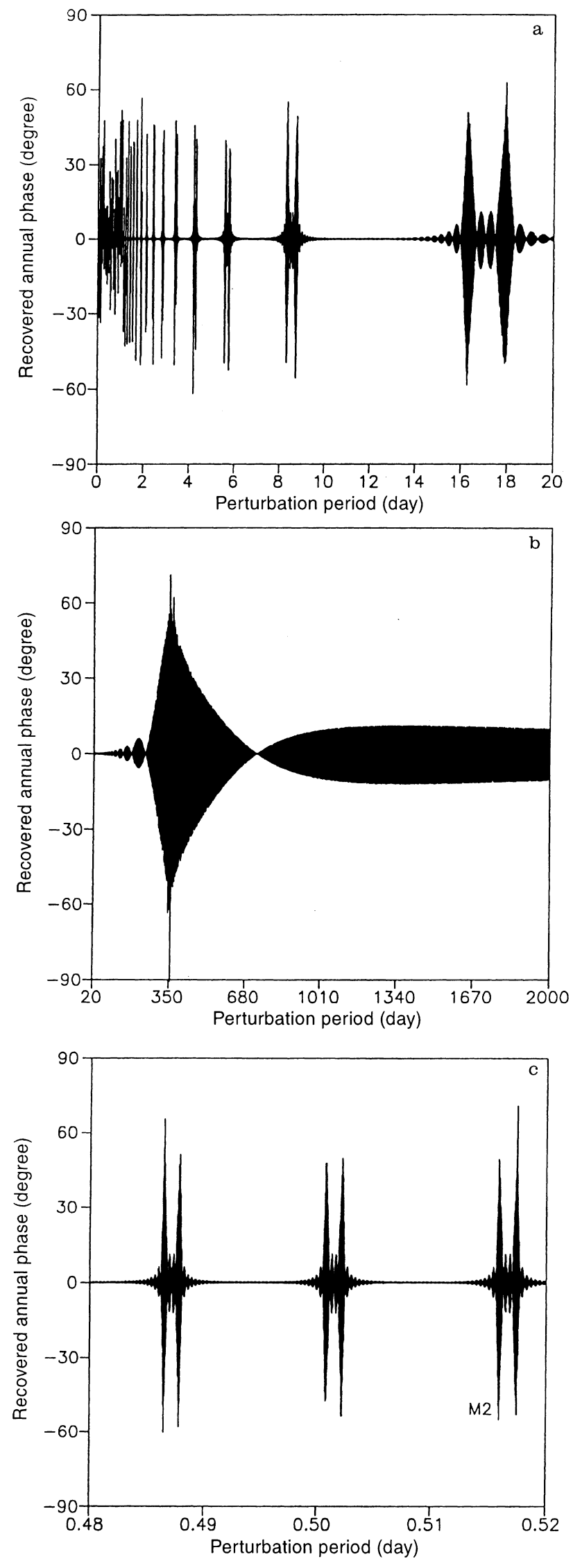

Fig. 3a-c. As Fig. 2, but for the recovered phase 
interesting to note that in the middle of each spike pair, both the amplitude and the phase have a zero discrepancy, meaning that perturbations at these periods have no impact on the recovery of annual signal. This property offers a possibility to eliminate a specific tidal contamination on a wanted frequency. For example, if the satellite orbit is chosen at a period which causes the M2 period to be in the middle of one of the spike pairs shown in Fig. 2a, a major part of its contamination to the annual harmonic will then be removed.

In order to examine the impact of data duration on the recovery of annual amplitude and phase, we increase the simulation time from 2 to 4 years. It is found that the general structure of the aliasing part has very little change compared to Figs. 2a,c and 3a,c, except that the spikes appear to be slightly sharper (not shown). Beyond the Nyquist period, however, the interference pattern has been significantly altered (Fig. 4a). This is exhibited
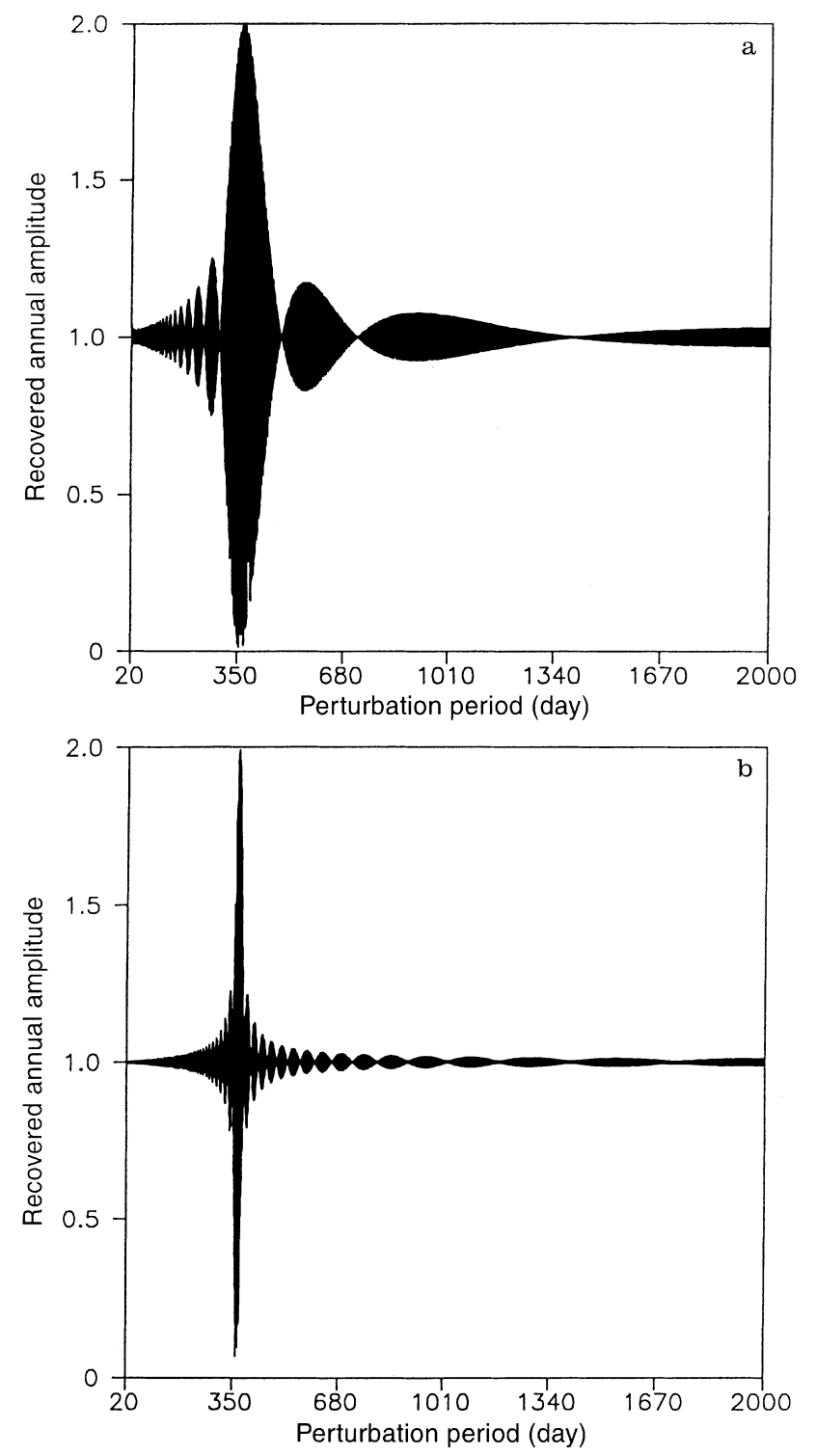

Fig. 4. a As Fig. 2b, but for a simulation duration of 4 years; b Same as Fig. 2b, but for a simulation duration of 20 years under the sampling scheme of TOPEX/POSEIDON by the narrowing of the main annual band and the addition of several non-interference points. As a result, an increase in data duration leads to a decrease in interannual contamination. But knowing the fact that the actual Exact Repeat Mission of Geosat lasted for about 26 months (Cheney et al., 1991), Fig. 2b represents a more realistic picture than Fig. 4a. An example of possible future interest is shown in Fig. $4 \mathrm{~b}$, which is obtained from the simulation of TOPEX/POSEIDONlike missions for a period of 20 years (expected from TOPEX/POSEIDON and its follow-ons). It is apparent that with a time-series of 20 years, the effect of nonannual interference will be considerably minimized.

Returning to Fig. 2b, we now increase the ratio of amplitude of signal versus perturbation from 1 to 2 , and plot the simulation result in Fig. 5. This time, there is no change in the general pattern of interference except that the recovered amplitude fluctuation has been reduced by a factor of 2 compared to Fig. 2b. Therefore, the fluctuation amplitude is found to be inversely proportional to the ratio of signal to perturbation.

Next, we have an insight into the situation at crossover points where both ascending and descending samples are available. Again we plot the recovered amplitude and phase of the annual signal as a function of perturbation period using as input the altimeter data from both ascending and descending tracks. This time, however, we find little change in the unaliased part, but considerable changes are observed within the Nyquist band (Fig. 6a). The typical impact of combining ascending and descending data is that the deviations of both the recovered amplitude and phase are systematically reduced, particularly for some of the spikes (compare Figs. 2a and 6a). However, the locations of the spikes remain unchanged (Fig. 6a). An extreme case may occur in which all other spike pairs disappear (Fig. 6b,c, also compare with Fig. 2a,c). The exact impact of the combination on a particular signal period

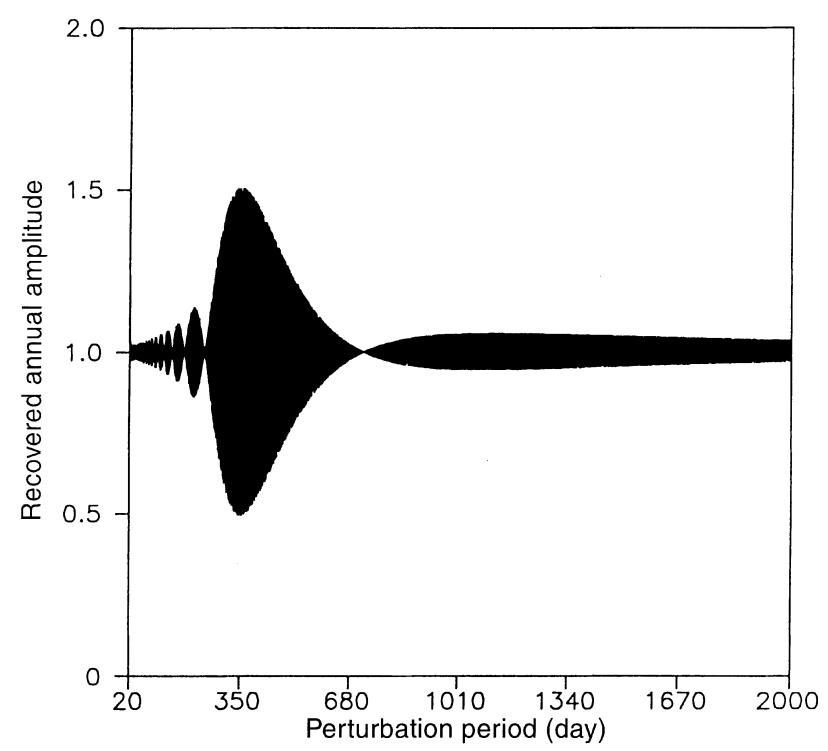

Fig. 5. Same as Fig. 2b, except that the ratio of amplitude of signal versus perturbation is 2 

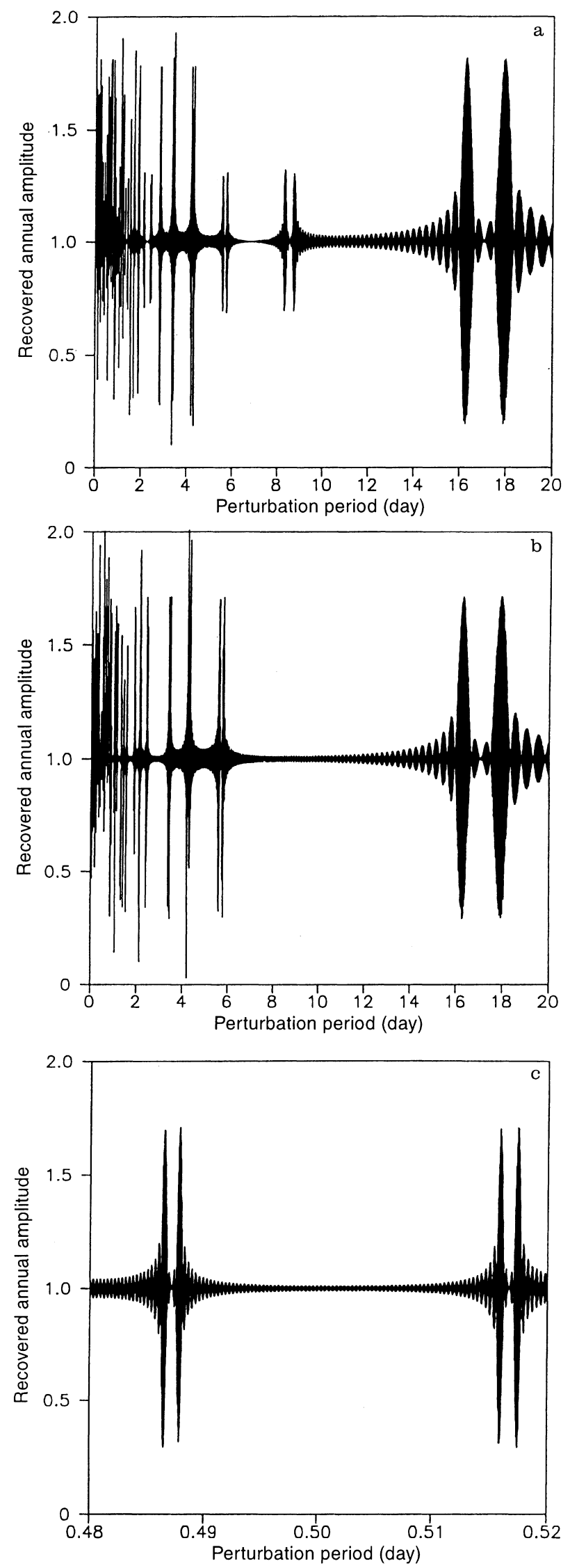

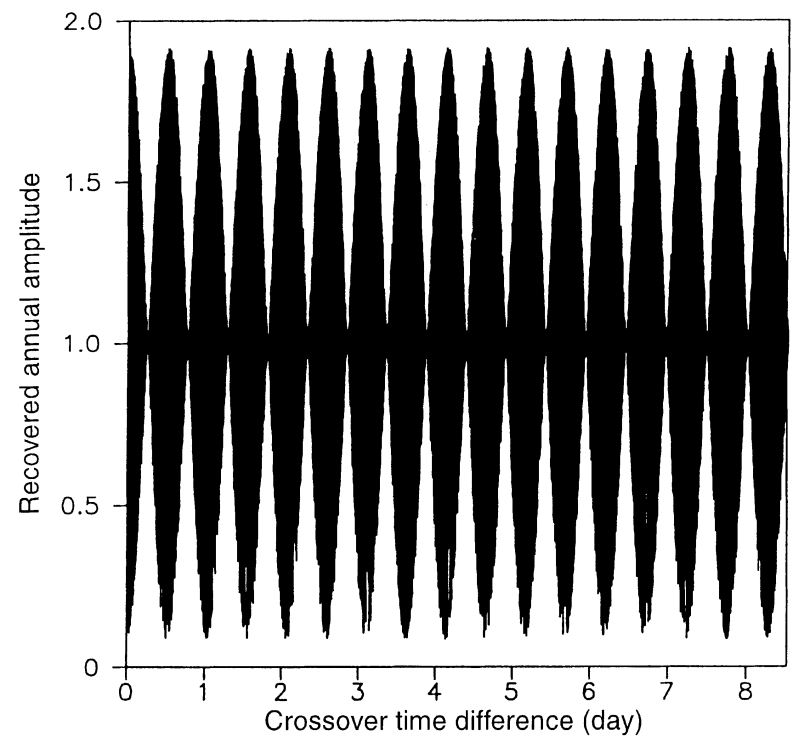

Fig. 7. The recovered amplitude of an annual harmonic signal with respect to the crossover time difference between successive ascending and descending samples. The M2 tide is used as perturbation and the simulation duration is 2 years

depends critically on the time difference of ascending and descending measurements which varies from 0 to $T_{s} / 2$ with latitude. The recovered amplitude, from the annual signal and a perturbation of the M2 tide, with respect to the crossover time difference, is shown in Fig. 7, which appears as a periodic oscillation. It should be pointed out that the consequences of some of the effects discussed have also been observed with real Geosat data (e.g., Jacobs et al., 1992).

In summary, numerical simulations demonstrate that altimeter-derived annual cycle of sea level is subjected to alias contamination of both tidal and non-tidal origins at short time-scales, and seasonal and interannual interference at long time-scales. The uncertainties of the recovered amplitude and phase are found to be coherent. It is also shown that the joint use of both ascending and descending samples at crossover points may partly remove the alias contamination, and the extension of data duration may partly reduce the interannual interference. However, knowing the heavy potentials of contamination in theory and the complex nature of the sea-level spectrum in reality, it seems difficult for an annual sea-level signal to be separated faithfully from existing altimeter measurements. Therefore, care must be taken when such results are interpreted or compared.

Fig. 6a-c. The recovered amplitude of an annual harmonic signal with respect to the perturbation period. The simulation is performed with data from both ascending and descending tracks at crossover points for a duration of 2 years. The time difference between two successive ascending and descending samples is $\mathbf{a} T_{s} / 5$ and $\mathbf{b} T_{s} / 4 ; \mathbf{c}$ is a zoom of $\mathbf{b}$ 


\section{Case 2: annual Rossby waves}

Rossby waves in the ocean are westward propagation with a time-scale of several days to several years and a space-scale of kilometers to several thousand kilometers (Magaard, 1983; Jacobs et al., 1993). They are the dynamic mechanism for the transient of the ocean to changes in large-scale atmospheric forcing. It has been recently suggested that Rossby waves generated by El Niño events may account for ocean circulation anomalies a decade later in the mid-latitude North Pacific (Jacobs et al., 1994). Such ocean changes may significantly influence weather patterns over North America. Observations of Rossby waves have been an area of active research in satellite altimetry since Geosat data became available in the late 1980s [see Chelton and Schlax (1996) for an overview]. Many of the authors have used time/longitude diagrams of sea surface height to identify Rossby waves, since these diagrams are thought to provide a direct means for deriving propagationrelated parameters such as period, wavelength and phase speed. Recently, there have been some suspicions regarding the validity of some of these Rossby waves, following the recognition of the confusion between Rossby-wave propagation and aliased tidal propagation (Jacobs et al., 1992, 1993; Schlax and Chelton, 1994a,b). For example, Schlax and Chelton (1994a,b) have proved that at least part of the Rossby-wave-like propagation in the North Atlantic observed by Tokmakian and Challenor (1993) is actually the aliased M2 tide.

We will demonstrate the confusion between annual Rossby wave and aliased M2 tide through a numerical simulation of this example. To obtain a more realistic picture, five other major tidal constituents listed in Table 1 are also incorporated. And for the purpose of comparison, similar simulations are performed with ERS and TOPEX/POSEIDON. The simulation scheme is as follows. We first use the alias periods and wavelengths as well as the normalized equilibrium amplitudes of the six major tidal constituents to construct three 180-day data sets under the sampling schemes of Geosat, ERS and TOPEX/POSEIDON along $0-60^{\circ} \mathrm{E}$ at a given latitude. The simulated sea surface height $H(I, J)$ at longitude $x(I)$ and time $t(J)$ is computed through

$$
H(I, J)=\frac{\sum_{i=1}^{6} w_{i} \sin \left[2 \pi\left(\frac{x(I)}{\lambda_{a, i}}+\frac{t(J)}{T_{a, i}}\right)\right]}{\sum_{i=1}^{6} w_{i}}
$$$$
(I, J=1,2,3, \ldots \ldots) \text {, }
$$

where $w_{i}$ are the equilibrium amplitudes of the M2, S2, $\mathrm{N} 2, \mathrm{~K} 1, \mathrm{O} 1$ and P1 tides, for which values of 0.90809 , $0.42248,0.17386,0.53011,0.37694$ and 0.17543 are taken, respectively. Variables $x$ and $t$ are subjected to the following constraints defined by the satellite sampling scheme,

$$
x(I+1)=x(I)+\Delta x
$$

$$
\begin{aligned}
& t(I, J+1)=t(I, J)+T_{s}, \\
& t(I+1, J+1)=t(I, J)+\Delta t,
\end{aligned}
$$

where $\Delta x=1.475^{\circ}, T_{s}=17.0505$ days, $\Delta t=3.0048$ days for Geosat, $\Delta x=0.719^{\circ}, T_{s}=35.0$ days, $\Delta t=15.998$ days for ERS, and $\Delta x=2.835^{\circ}, T_{s}=9.9156$ days, $\Delta t=2.967$ days for TOPEX/POSEIDON. In the present case, we restrict $0 \leq x \leq 60^{\circ}$ and $0 \leq t \leq 180$ days. The initial phases of all six tidal constituents are set to 0 , since they are found to be insensitive to the general propagation patterns.

Based on the simulation data created by Eqs. (10) and (11), three time/longitude diagrams corresponding to Geosat, ERS and TOPEX/POSEIDON are plotted in a, b, c of Fig. 8, respectively. As expected, alias tidal propagation is dominated by the M2 tide. For the case of Geosat, it is characterized by a series of westward propagating waves with a period of around 10 months and a wavelength of $8^{\circ}$, which appears to be very similar to those observed by Geosat altimetry as annual Rossby waves in the literature. In contrast, eastward propagation with a period of roughly 90 days and a wavelength of $8^{\circ}$ is produced by ERS altimetry (Fig. 8b). In Fig. 8c, the TOPEX/POSEIDON derived tidal propagation also shows up as eastwards-travelling waves but with an alias period of about 60 days and an alias wavelength of $9^{\circ}$. As a byproduct of this simulation, we would like to address two additional points.

1. The diversity of the outcome. Comparing $\mathrm{a}, \mathrm{b}$ and $\mathrm{c}$ of Fig. 8, it is difficult to imagine that they result from the observations of exactly the same signals at the same location during the same period. They are so different in temporal and spatial scales that one may wonder how realistically each of them can represent the reality and how well they can compare with each other. Moreover, keeping in mind such a diversity resulting from regular tidal signals, we naturally have to be more cautious with altimeter-observed Rossby waves with various frequencies and wavelengths.

2. The phase speed of alias tidal propagation can be estimated through

$v_{a}=\frac{\pi \lambda_{a} R_{e} \cos \phi}{180 T_{a}}$,

where $R_{e}$ is the radius of the earth on the equator and $\phi$ is the latitude. The so-computed phase speed of the M2 tide is $2.2 \mathrm{~cm} / \mathrm{s}$ (westward) for Geosat, $8.5 \mathrm{~cm} / \mathrm{s}$ (eastward) for ERS, and $13.2 \mathrm{~cm} / \mathrm{s}$ (eastward) for TOPEX/POSEIDON at mid-latitude. It is necessary to note that the phase speeds obtained from Eq. (12) (back to Eqs. (1) and (2)) are totally determined by the altimeter sampling scheme and the original period of the signal. They do not carry any information about the real propagation in the ocean. This is why the same M2 tide appears as westward propagation in Geosat and eastward propagation in ERS and TOPEX/POSEIDON. Likewise, for signals within the Nyquist band the alias phase speeds estimated from time/longitude diagrams of sea surface height do not represent the real propagation in terms of both magnitude and direction. Therefore, 

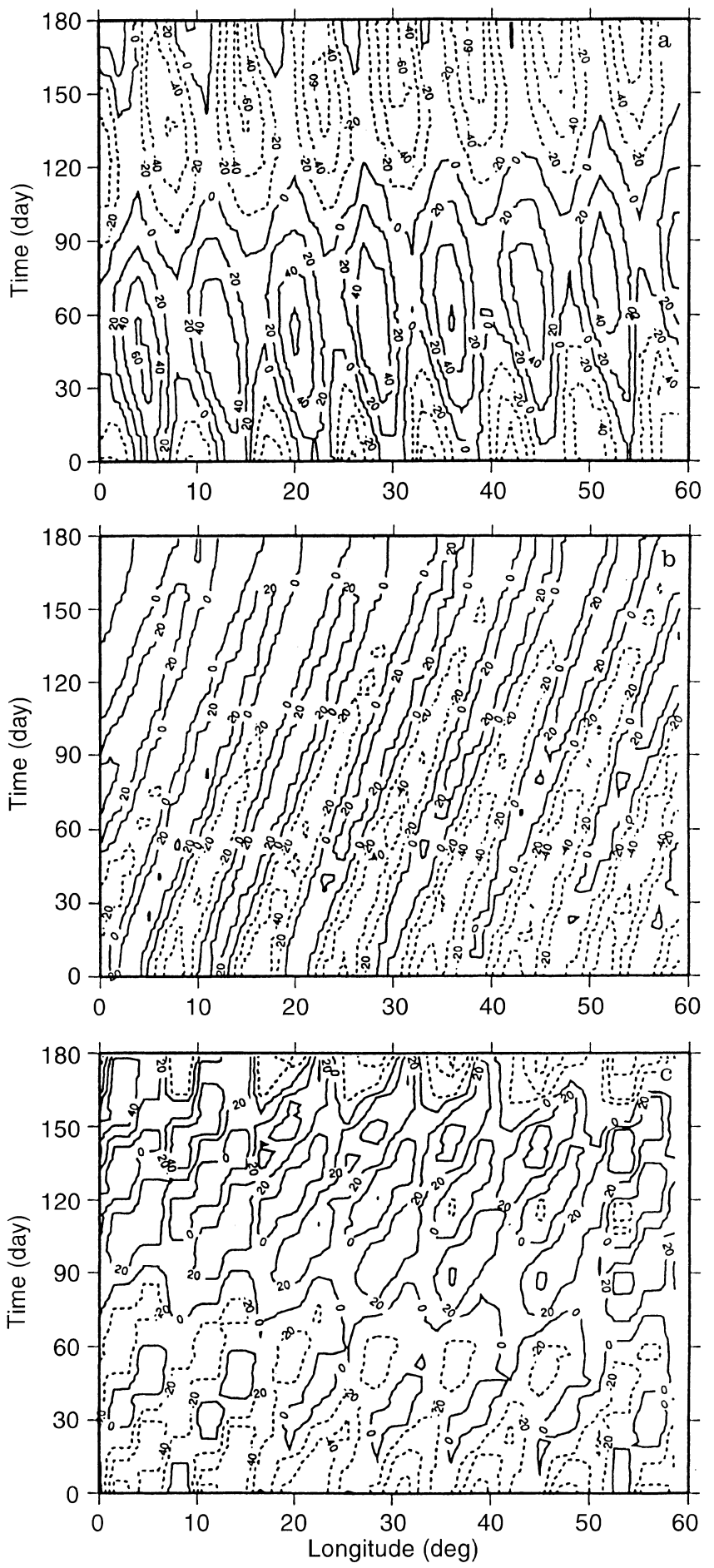

Fig. 8a-c. Time/longitude diagrams of simulated propagation of the combined six major tidal constituents under the sampling scheme of a Geosat, b ERS and c TOPEX/POSEIDON. The contours have been multiplied by 100 and the interval is 20 . Solid and dashed lines denote positive and negative values, respectively

efforts to extract the real phase speed of such signals through alias wave propagation on the basis of altimetric time/longitude diagrams are unattainable.

Now we go one step further in demonstrating the full aliasing potential related to annual-Rossby-wave observations. Based on the alias theory represented by Eqs.
(1) and (2), alias period/wavelength windows corresponding to Geosat, ERS and TOPEX/POSEIDON with compatible time/space-scales to an annual Rossby wave, i.e. 305 days $<\left|T_{a}\right|<425$ days, $2^{\circ}<\left|\lambda_{a}\right|<10^{\circ}$ and $T_{a} \times \lambda_{a}>0$ (which ensures a westward propagation), are shown in Fig. 9. It is evident that numerous signals with periods of less than 20 days might appear in time/longitude diagrams as annual-Rossby-wave-like propagation, provided they have large enough amplitudes. Obviously, TOPEX/POSEIDON (Fig. 9a) has the least probability of running into the confusion between real and false annual Rossby waves compared to ERS (Fig. 9b) and Geosat (Fig. 9c). The M2 tide described is only one of the numerous elements in the Geosat window (see Fig. 9d for a zoom). To illustrate a nontidal case, a candidate signal with a period of 16.29 days in the Geosat window (Fig. 9c) is selected, and its time/ longitude diagram is plotted in Fig. 10. One can see that the propagation appears to be westward with an alias period of 365.2 days and an alias wavelength of $8.37^{\circ}$. Therefore, non-tidal signals may introduce exactly the same confusion as tidal signals, as far as annual Rossby waves are concerned. Since Rossby waves usually appear as regional features in altimeter observations, the dominance of a non-tidal signal in a limited area may easily be misinterpreted as Rossby waves, provided it falls into the alias window.

As a summary of this section, a general conclusion might be drawn. Annual-Rossby-wave-like propagation as observed by altimetry may result from either real annual Rossby waves or any of the signals falling into the alias Rossby window (Fig. 9) as long as they have significant amplitudes. In the latter situation, the signals are known to have periods of less than 20 days and therefore they are certainly not annual Rossby waves, although the possibility of their Rossby-wave origin cannot be completely ruled out. In addition, it is worth mentioning the recent finding by Chelton and Schlax (1996) that the TOPEX/POSEIDON-observed propagation speeds of Rossby waves are systematically higher than those predicted from standard theory. Suppose the tidal part of aliasing does not undermine the finding due to the carefully selected orbit configuration; could the non-tidal aliasing be a factor to take into account?

\section{Concluding remarks}

The full aliasing potentials in altimeter sea-level observations associated with two important geophysical cases, the seasonal sea-level variability and the annual Rossby wave, are analysed in this study. The first case focuses on the alias impacts on the recovery of the amplitude and phase of an annual harmonic signal (involving $z$ and $t$ dimensions), while the second case illustrates the alias consequences on some propagation related properties (involving $x, y$ and $t$ dimensions). Theoretical and numerical results suggest that aliasing in satellite altimetry is an intrinsically $4 \mathrm{D}(x, y, z$ and $t)$ process including both tidal and non-tidal contributions. As a result, systematic aliasing contamination exists in 

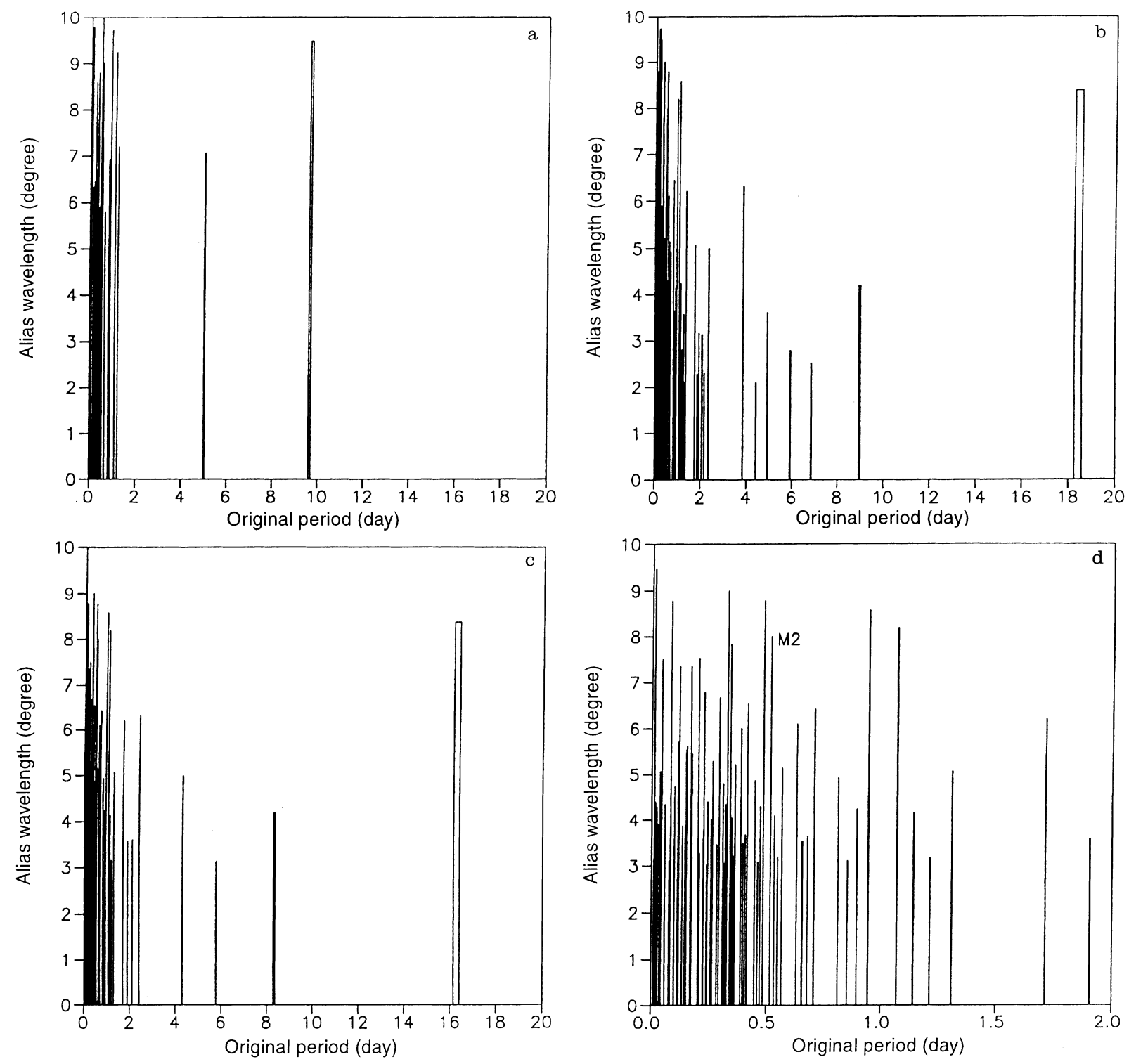

Fig. 9a-d. Alias windows of Rossby waves with $305<\left|T_{a}\right|<425$ days and $2^{\circ}<\left|\lambda_{a}\right|<10^{\circ}$ under the sampling schemes of a TOPEX/ POSEIDON, b ERS (35-day repeat orbit), and $\mathbf{c}$ Geosat; $\mathbf{d}$ is a zoom of $\mathbf{c}$ with the original period of the signal varying from 0 to 2 days

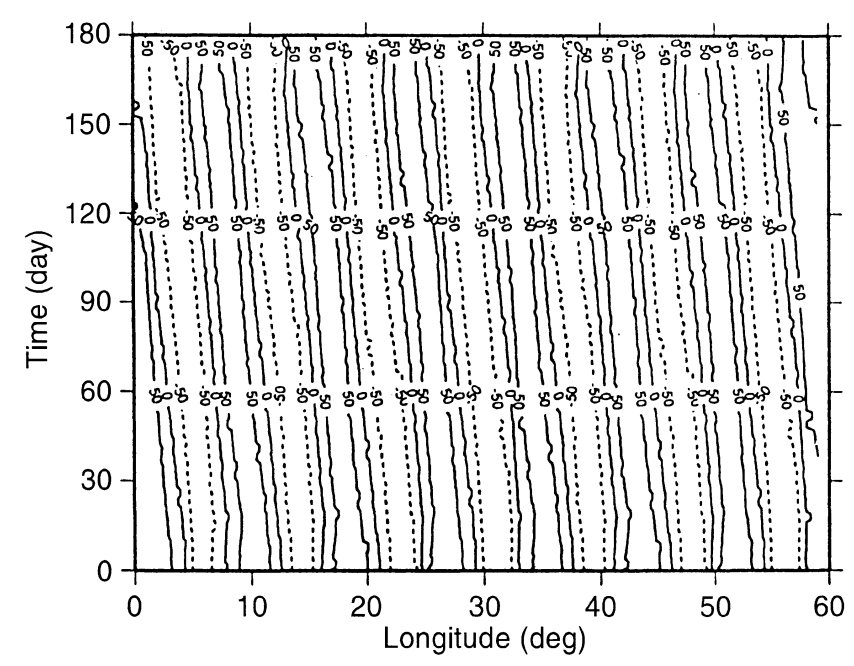

all altimeter measurements. Although most of the simulations here are performed under the Geosat sampling scheme, it is obvious (through comparison of a-c of Fig. 1) that similar results and conclusions can be expected from TOPEX/POSEIDON and ERS altimeters. At the present time and on global scale, aliasing is likely to be dominated by residual tides. However, one has to understand that the tidal part of the total aliasing is theoretically or empirically approachable due to its

Fig. 10. Annual-Rossby-wave-like alias propagation of a harmonic signal with a unit amplitude and a period of 16.29 days observed under the Geosat sampling scheme. The contours have been multiplied by 100 and the interval is 50 . Solid and dashed lines denote positive and negative values, respectively 
well-defined dynamics and frequencies, while the nontidal part has an irregular nature in terms of scale, intensity and geographical distribution. With the continuous improvements in the accuracy of tide models, the non-tidal contamination will become relatively more important, as happened to the relationship between orbital error and tidal error in the past few years (see, e.g., Stammer and Wunsch, 1994). In fact, this might have already been the case for some regional altimetric applications, though without our being aware of it. Therefore, it seems to us that now is the time to present this technical contribution as a cautious warning regarding this potential problem. Meanwhile, we have to regard the present analysis as highly preliminary. Possible questions of future concern may include the aliasing behaviour of multi-altimeter cases, the impact of data-processing techniques, such as filtering and smoothing, on alias properties, etc. The results of these studies will appear in subsequent papers.

Acknowledgements. Topical Editor D. Webb thanks D. Cromwell and P. Vincent for their help in evaluating this paper. This work has benefited from a grant of the French Foreign Affairs Ministry in support of Ge Chen's stay at IFREMER

\section{References}

Aoki, S., S. Imawaki, and K. Ichikawa, Baroclinic disturbances propagating westward in the Kuroshio Extension region as seen by a satellite altimeter and radiometers, J. Geophys. Res., 100, 839-855, 1995.

Chelton, D. B., and M. G. Schlax, Global observations of oceanic Rossby waves, Science, 272, 234-238, 1996.

Chelton, D. B., M. G. Schlax, D. L. Witter, and J. G. Richman, Geosat altimeter observations of the surface circulation of the Southern Ocean, J. Geophys. Res., 95, 17877-17903, 1990.

Chen, G., and R. Ezraty, Alias impacts on the recovery of sea-level amplitude and energy from altimeter measurements, Int. J. Remote Sensing, 17, 3567-3576, 1996.

Cheney, R. E., N. S. Doyle, B. C. Douglas, R. W. Agreen, L. Miller, E. L. Timmerman, and D. C. McAdoo, The complete Geosat altimeter GDR handbook, NOAA Manual NOS NGS 7, National Ocean Service, Rockville, Md., 1991.

Cheney, R., L. Miller, R. Agreen, N. Doyle, and J. Lillibridge, Topex/Poseidon: The 2-cm solution, J. Geophys. Res., 99, 24555-24563, 1994

Didden, N., and F. Schott, Seasonal variations in the western tropical Atlantic: surface circulation from Geosat altimetry and WOCE model results, J. Geophys. Res., 97, 3529-3541, 1992.

Fu, L.-L., E. J. Christensen, C. A. Yamarone, M. Lefebvre, Y. Ménard, M. Dorrer, and P. Escudier, TOPEX/POSEIDON mission overview, J. Geophys. Res., 99, 24369-24381, 1994.

Jacobs, G. A., G. H. Born, M. E. Parke, and P. C. Allen, The global structure of the annual and semiannual sea surface height variability from Geosat altimeter data, J. Geophys. Res., 97, 17813-17828, 1992.
Jacobs, G. A., W. J. Emery, and G. H. Born, Rossby waves in the Pacific Ocean extracted from Geosat altimeter data, J. Phys. Oceanogr., 23, 1155-1175, 1993.

Jacobs, G. A., H. E. Hurlburt, J. C. Kindle, E. J. Metzger, J. L. Mitchell, W. J. Teague, and G. J. Wallcraft, Decade-scale transPacific propagation and warming effects of an El Niño anomaly, Nature, 370, 360-363, 1994.

Knudsen, P., Global low harmonic degree models of the seasonal variability and residual ocean tides from TOPEX/POSEIDON altimeter data, J. Geophys. Res., 99, 24643-24655, 1994.

Le Provost, C., M. L. Genco, F. Lyard, P. Vincent, and P. Canceil, Spectroscopy of the world ocean tides from a finite element hydrodynamic model, J. Geophys. Res., 99, 24777-24797, 1994.

Le Traon, P. Y., P. Gaspar, F. Bouyssel, and H. Makhmara, Using Topex/Poseidon data to enhance ERS-1 data, J. Atmos. Ocean Technol., 12, 161-170, 1995.

Levitus, S., Climatological Atlas of the World Ocean, NOAA Prof. Rap. 13, 1982.

Luther, D. S., Evidence of a 4-6-day barotropic, planetary oscillation of the Pacific Ocean, J. Phys. Oceanogr., 12, 644-657, 1982.

Magaard, L., On the potential energy of baroclinic Rossby waves in the North Pacific, J. Phys. Oceanogr., 13, 38-42, 1983.

Nerem, R. S., E. J. Schrama, C. J. Koblinsky, and B. D. Beckley, A preliminary evaluation of ocean topography from the Topex/ Poseidon mission, J. Geophys. Res., 99, 24565-24583, 1994.

Périgaud, C., Sea-level oscillations observed with Geosat along the two shear fronts of the Pacific North Equatorial Countercurrent, J. Geophys. Res., 95, 7239-7248, 1990.

Périgaud and Delecluse, Annual sea level variations in the southern tropical Indian ocean from Geosat and shallow-water simulations, J. Geophys. Res, 97, 20169-20178, 1992.

Provost, C., and P. Y. Le Traon, Spatial and temporal scales in altimetric variability in the Brazil-Malvinas current confluence region: dominance of the semiannual period and large spatial scales, J. Geophys. Res., 98, 18037-18051, 1993.

Schlax, M. G., and D. B. Chelton, Detecting aliased tidal errors in altimeter height measurements, J. Geophys. Res., 99, 1260312612, 1994a.

Schlax, M. G., and D. B. Chelton, Aliased tidal errors in Topex/ Poseidon sea surface height data, J. Geophys. Res., 99, 2476124775, 1994b.

Shum, C. K., J. C. Ries, and B. D. Tapley, The accuracy and applications of satellite altimetry, Geophys. J. Int., 121, 321-336, 1995.

Stammer, D., and C. Wunsch, Preliminary assessment of the accuracy and precision of Topex/Poseidon altimeter data with respect to the large-scale ocean circulation, J. Geophys. Res., 99, 24584-24604, 1994.

Tapley, B. D., D. P. Chambers, C. K. Shum, R. E. Eanes, and J. C. Ries, Accuracy assessment of the large-scale dynamic ocean topography from Topex/Poseidon altimetry, J. Geophys. Res., 99, 24605-24617, 1994.

Tokmakian, R. T., and P. G. Challenor, Observations in the Canary Basin and the Azores frontal region using Geosat data, $J$. Geophys. Res., 98, 4761-4773, 1993.

Wunsch, C., and A. E. Gill, Observation of equatorially trapped waves in Pacific sea level variations, Deep Sea Res., 23, 371-390, 1976.

Zlotnicki, V., L. -L. Fu, and W. Patzert, Seasonal variability in global sea level observed with Geosat altimetry, J. Geophys. Res., 94, 17959-17969, 1989. 